\title{
La alfabetización académica: aportes desde la clase de comprensión lectora de textos en inglês
}

DOI: $10.46932 / \mathrm{sfjdv2n2-101}$

Received in: March 1st, 2021

Accepted in: May 30th, 2021

\author{
Silvia Déborah Grodek \\ Universidad Nacional de Tucumán (UNT) \\ Facultad de Filosofía y Letras \\ Las Acacias 87, Yerba Buena \\ Tucumán, Argentina \\ E-mail: silviagrodek@gmail.com
}

\begin{abstract}
Al ingresar al ámbito universitario, los estudiantes recién egresados del nivel secundario enfrentan diferentes tipos de dificultades de diferentes tipos. En este sentido, uno de los principales obstáculos que estos alumnos deben abordar tiene que ver con el desarrollo de competencias de lectura de los géneros que habitualmente circulan en el ámbito académico.

En Argentina, estas dificultades han sido reconocidas y abordadas de diferentes maneras y con variados resultados. Así, una de las modalidades más frecuentes de intervención pedagógica en el contexto universitario ha sido la implementación de talleres de comprensión lectora que, en muchos casos, no ha logrado solucionar el problema de manera efectiva.

Entendemos que, para ser miembro de una comunidad académica y científica, como es el caso de la comunidad universitaria, es necesario dominar los géneros discursivos propios de la misma. Desde la cátedra Idioma Moderno, Inglés II nos planteamos la necesidad de brindar nuestro aporte para la inserción del estudiante en las comunidades disciplinares y profesionales, las cuales poseen prácticas discursivas propias.

En este trabajo tomaré como base el concepto de alfabetización académica, el cual implica "el conjunto de nociones y estrategias necesarias para participar en la cultura discursiva de las disciplinas, así como en las actividades de producción y análisis de textos requeridas para aprender en la universidad" (Carlino, 2005: 13). Desde un enfoque funcional y sociocultural del concepto de alfabetización académica, entendemos que en nuestras clases de lectura en lengua extranjera podemos colaborar en el desarrollo de estrategias de comunicación en nuestros estudiantes, y fomentar en ellos el desarrollo de habilidades para "aprender a aprender" en el ámbito universitario.

El objetivo de este trabajo es brindar una reflexión acerca de las diferentes prácticas de lectura implementadas en nuestra cátedra y que contribuyen a la alfabetización académica de nuestros estudiantes. Estas reflexiones se basan en experiencias llevadas a cabo en nuestras clases, así como también en estudios desarrollados con nuestros alumnos en los últimos años.
\end{abstract}

Palabras clave: alfabetización académica, lectura, lengua extranjera, géneros

\section{INTRODUCCIÓN}

La inserción en la vida universitaria presenta numerosas dificultades a los estudiantes que recién egresan del nivel secundario. 
Uno de los principales problemas que estos estudiantes deben enfrentar está relacionado con la necesidad de construir conocimientos específicos a través de prácticas académicas que les permitan constituirse como miembros de la comunidad disciplinar correspondiente a la carrera universitaria que están cursando. En este sentido, la lectura y la escritura en el contexto universitario se presentan como las principales herramientas intelectuales para la construcción del conocimiento disciplinar.

Este trabajo se focalizará en las problemáticas relacionadas con el desarrollo de competencias de comprensión lectora de los géneros que habitualmente circulan en el ámbito académico. En el mismo se presentarán reflexiones acerca de los aportes que intentamos brindar desde la cátedra Idioma Moderno, Inglés II de la Facultad de Filosofía y Letras de la UNT, como mediadores para que el estudiante universitario desarrolle estrategias cognitivas y metacognitivas de comprensión lectora que le permitan insertarse en la comunidad académica.

Si bien entendemos que es necesario que se enseñe a leer desde cada una de las disciplinas a través de actividades y estrategias de lectura propias de las prácticas discursivas con las que cada disciplina construye el conocimiento, sentimos que nuestra asignatura no puede permanecer indiferente a la necesidad de que todos los docentes de la universidad nos involucremos en el proceso de alfabetización académica de nuestros estudiantes. Coincidimos con Paula Carlino cuando sostiene que: "resulta preciso admitir que aprender a leer y escribir para propósitos específicos no es incorporar técnicas ni practicar análisis discursivos sino involucrarse en un proceso de enculturación (Prior y Bilbro, 2011), lo cual incluye adquirir herramientas para desenvolverse en una actividad social mientras se participa en ella" (Carlino, 2013: 361)

\section{ALGUNAS CONSIDERACIONES TEÓRICAS}

Este trabajo se inscribe en el marco de la didáctica de las lenguas extranjeras, más precisamente en la enseñanza de la lecto-comprensión de textos académicos en inglés en el medio universitario.

Teniendo en cuenta el contexto en el que nos situamos, en este trabajo adherimos a la concepción de lectura planteada por la Dra. Raquel Pastor, dentro del marco del interaccionismo social vygotskiano, quien afirma que la misma es "concebida como una actividad de carácter social que se adquiere a través de situaciones y de prácticas interiorizadas por el sujeto durante su confrontación con los diversos escritos que circulan en su socio-cultura.” (Pastor, 2005: 1).

Dentro de esta misma línea conceptual, Dorronzoro y Klett definen a la lectura "como una actividad del lenguaje, que resulta de un aprendizaje social, estrechamente relacionada con los contextos socioculturales en los que se lleva a cabo y, por lo tanto, con las actividades concretas, propias de ese contexto, en las cuales se origina." (Dorronzoro, Klett, 2006:58) 
Estas mismas autoras definen a la lectura en lengua extranjera como “...el proceso de construcción de sentido llevado a cabo por un lector, que forma parte de una determinada comunidad disciplinar, a partir de un texto escrito en un idioma que no es el materno, y mediante el diálogo establecido con el autor, con el propósito de construir conocimientos dentro de un área específica". (Dorronzoro y Klett, 2006: 59)

Sobre la base de las posiciones teóricas presentadas, se refuerza la postura de que aprender a leer en lengua extranjera implica comprender cómo funcionan los textos dentro del contexto sociohistóricocultural en el que se insertan y circulan. Aprender a leer discursos de una disciplina y de tipos de textos determinados implica un proceso de inserción en una comunidad discursiva y disciplinar que tiene determinados modos de ver e interpretar el mundo, y por lo tanto, tiene maneras específicas de producir e interpretar sus propios textos.

Tomamos como referencia una primera definición de alfabetización académica de Paula Carlino: "conjunto de nociones y estrategias necesarias para participar en la cultura discursiva de las disciplinas así como en las actividades de producción y análisis de textos requeridas para aprender en la universidad" (Carlino, 2006:13). Esta misma autora diez años después redefine el concepto (2013) afirmando que: “Alfabetizar académicamente equivale a ayudar a participar en prácticas discursivas contextualizadas, lo cual es distinto de hacer ejercitar habilidades que la fragmentan y desvirtúan" (Carlino, 2013:370)

En consecuencia, entendemos que desde la clase de comprensión lectora de textos académicos en inglés no pretendemos ofrecer soluciones definitivas, sino contribuir a la formación de lectores académicos a partir del desarrollo de prácticas lectoras contextualizadas. Retomando planteos realizados por Paula Carlino, coincidimos con ella cuando afirma que: "De acuerdo con las teorías del aprendizaje situado (Brown, Collins y Duguid, 1989), y la concepción de la escritura y lectura como actividades o prácticas sociales (en contraposición a técnicas o destrezas independientes de su contexto de uso) (Artemeva, 2008; Lea y Street, 1998; Russell, 1990), las prácticas se aprenden por participación in situ. Ningún espacio curricular único y delimitado permite desarrollar una competencia general, abstracta, que luego por su cuenta los alumnos podrían aplicar al resto de las asignaturas” (Carlino, 2013, pp 360-361)

De modo que, si bien nuestras clases de Idioma Moderno, Inglés II constituyen un ámbito propicio para generar experiencias de lectura y de reflexión con textos disciplinares y característicos del ámbito académico, "no forja "la" capacidad de hacerlo de una vez para siempre y en solitario" (Carlino, 2013, 360)

Aunque insistimos en que la enseñanza de la lectura en la universidad debería ser abordada en todas las materias de cada una de las carreras, desde las clases de nuestra asignatura ofrecemos a nuestros 
estudiantes universitarios orientaciones para que conozcan prácticas discursivas características del ámbito académico y disciplinar como una manera de fortalecer y enriquecer el proceso de alfabetización académica de nuestros alumnos. En este sentido, el eje que atraviesa las diferentes prácticas de lectura que realizamos en nuestras clases son los géneros del discurso académico. Entendemos que para poder participar en las prácticas discursivas propias de las diferentes esferas de la actividad social es necesario hacerlo a través de los géneros discursivos disponibles. Por lo tanto, consideramos que los mismos constituyen un elemento fundamental en la enseñanza y aprendizaje de las habilidades lingüísticocomunicativas.

Cuando hablamos de géneros discursivos, seguimos los postulados de Bajtin, quien sostiene lo siguiente: "El uso de la lengua se lleva a cabo en forma de enunciados (orales y escritos) concretos y singulares que pertenecen a los participantes de una esfera de la praxis humana." (Bajtin,1990:248) Este autor afirma que: "Cada enunciado separado es, por supuesto, individual, pero cada esfera del uso de la lengua elabora sus tipos relativamente estables de enunciados, a los que denominamos géneros discursivos." (Bajtin,1990, 248)

De modo que los géneros reflejan las esferas sociales tanto en el contenido temático, el estilo, los recursos léxicos y gramaticales, así como en su composición o estructuración. (Rodríguez Bello; Villegas, 2008).

Otro autor que destaca el carácter histórico y cultural de los géneros discursivos es Michael Swales (1990) Así, Swales sostiene que "Un género abarca una clase de eventos comunicativos, cuyos miembros comparten algún conjunto de propósitos comunicativos. Estos propósitos son reconocidos por los miembros expertos de la comunidad discursiva de origen, y por lo tanto constituyen la razón de ser del género. Esta razón de ser moldea la estructura esquemática del discurso e influye y limita la elección del contenido y del estilo" (Swales, 1990:58) Como vemos en esta definición, Swales pone un fuerte énfasis en el objetivo comunicativo y en las convenciones compartidas por la comunidad discursiva que lo utiliza.

\section{CARACTERÍSTICAS DE LA ASIGNATURA IDIOMA MODERNO, INGLÉS II}

La materia que dicto, Idioma Moderno, Inglés II, forma parte del ciclo de formación general de los planes de estudios de la mayoría de las carreras de la Facultad de Filosofía y Letras de la Universidad Nacional de Tucumán. Se trata de un segundo curso de lecto-comprensión que apunta a formar lectores autónomos y eficientes de textos de especialidad en inglés. Esto se fundamenta en el hecho de que gran parte de la bibliografía científica y académica en las distintas disciplinas del área de las humanidades está escrita en dicha lengua. Es así que, desde esta asignatura, buscamos fortalecer en nuestros alumnos sus 
competencias lectoras en lengua extranjera que les permitan tener acceso a las fuentes del conocimiento, esencial para su formación académica y profesional.

Por lo tanto, nuestra finalidad es guiar a los alumnos en el desarrollo de sus habilidades lectivas de modo que sean capaces de interpretar en forma ágil la bibliografía en inglés actualizada y presentada a través de distintos soportes. Para el logro de tal fin, nos planteamos diferentes objetivos específicos, tales como propiciar en el alumno una permanente reflexión acerca de las características del discurso académico en inglés en relación con los componentes lingüísticos y no lingüísticos del texto, así como también acerca de las estrategias de lectura más adecuadas para comprenderlo.

Debido a que la asignatura Idioma Moderno, Inglés II se ubica mayormente en el segundo año de los planes de estudio, nuestros alumnos son en general, novatos en sus conocimientos acerca de la disciplina, así como también con respecto a los tipos de discurso que habitualmente circulan en el ámbito universitario. Además, dado que nuestros estudiantes están cursando siete carreras diferentes, (Psicología, Filosofía, Historia, Letras, Ciencias de la Educación, Geografía y Trabajo Social), el grupo se caracteriza por una fuerte heterogeneidad en cuanto a las disciplinas. Más allá de estas diferencias disciplinares, todos comparten un mismo contexto social (el ámbito universitario y académico) y además tienen en común el hecho de que se encuentran en proceso de convertirse en lectores académicos. Es así que, para lograrlo, deben "aprender, más que cuestiones lingüísticas, discursivas o estratégicas, prácticas lectoras propias de una comunidad disciplinar que produce y comunica un determinado saber de un modo particular" (Dorronzoro, 2009: 98)

Teniendo en cuenta lo dicho anteriormente, desde nuestra cátedra, buscamos colaborar en dicho proceso de inserción a través de prácticas didácticas que focalicen en la estructura de los textos, debido a que entendemos que en las prácticas lectoras de dichas comunidades disciplinares el conocimiento del alumno-lector acerca de los géneros discursivos que habitualmente circulan en el ámbito académico influye en la reconstrucción del sentido del texto que realiza dicho lector. Dicho de otra manera, "la competencia textual de los lectores acerca de los géneros discursivos interviene efectivamente en la (re)construcción del texto" (Pastor, 2005: 7)

\section{APORTES HACIA LA ALFABETIZACIÓN ACADÉMICA DESDE LA CLASE DE LECTO- COMPRENSIÓN EN LENGUA EXTRANJERA}

A lo largo de los últimos años en la cátedra desarrollamos diferentes estudios exploratorios con nuestros estudiantes con el fin de ahondar en las problemáticas más frecuentes en la comprensión lectora de textos académicos escritos en inglés. Esas investigaciones que se realizaron mediante cuestionarios, encuestas y entrevistas individuales, arrojaron datos significativos acerca de las características de nuestros alumnos y de las dificultades en sus competencias lectoras. 
Como resultado de estos estudios, fuimos implementando diversas metodologías de trabajo que respondían a diferentes corrientes teóricas y metodológicas de la enseñanza de la lectura. Así, en un primer momento, pasamos por una etapa marcada por un enfoque estructuralista, con énfasis en las unidades morfológicas y sintagmáticas. Pero, al observar los limitados logros en la comprensión lectora de nuestros alumnos, adoptamos un enfoque cognitivo guiándolos en la aplicación de estrategias de lectura tendientes a la construcción de los diferentes niveles de representación mental del texto original, sobre la base de los modelos de Van Dijk y Kintsch (1983). Sin embargo, tanto las experiencias en clase como algunos estudios desarrollados nos llevaron a concluir que esta metodología de enseñanza no ofrecía los resultados esperados dado que estábamos descuidando un elemento central: el contexto. Así llegamos a la adopción de un enfoque contextual, que es el que implementamos actualmente, el cual se basa, como ya mencionamos en el marco teórico, en los postulados de la sociosemiótica de la lecto-comprensión.

Sobre la base de este último enfoque, desde nuestra cátedra nos propusimos acompañar a los alumnos en su proceso de alfabetización académica para ayudarlos a familiarizarse con prácticas del discurso típicas de la comunidad disciplinar a la que están incorporándose.

Partimos de la premisa de que el contexto es el marco en el que se inserta nuestra práctica pedagógica y es el que determina todos los demás aspectos que caracterizan a la misma.

Siguiendo el modelo sistémico-funcional de Halliday, vemos que este contexto se relaciona de manera dinámica con la lengua. En este sentido, al planificar y desarrollar nuestras clases, tenemos en cuenta que nuestro contexto de situación está constituido por tres variables: el campo, el tenor y el modo, los cuales producen tres tipos de significados: experienciales, interpersonales y textuales. Presentaré una descripción general de la manera en que enseñamos a leer en la cátedra tomando como marco las tres variables antes mencionadas.

\subsection{CAMPO}

El concepto de campo hace referencia al marco social en el que se llevan a cabo las prácticas comunicativas, así como al tema o asunto tratado.

Teniendo en cuenta esta variable, trabajamos en nuestras clases con textos de especialidad, propios del contexto académico y científico de las diferentes disciplinas y que se caracterizan por ser altamente formalizados. Se trata, entonces, de textos que expresan y transmiten conocimiento especializado abordando temáticas relacionadas con las carreras que cursan nuestros estudiantes.

Al tratarse de un grupo heterogéneo en cuanto a las especialidades, así como también al año de cursado (algunos son alumnos de $2^{\circ}$ o $3^{\circ}$ año y otros están finalizando sus carreras), se seleccionan textos que presenten información introductoria sobre los diferentes temas relacionados con las especialidades de 
modo tal que puedan ser abordados por cada uno de los estudiantes, presentando diferentes grados de especialización.

El hecho de que en nuestras clases participen estudiantes de diferentes áreas científicas nos exige generar instancias de intercambios con los docentes de las diferentes disciplinas dentro de nuestra facultad a fin de conocer las temáticas que se abordan en las asignaturas específicas y las prácticas de lectura propias de cada campo del saber. Estas dos cuestiones nos permiten seleccionar textos adecuados al grupo de alumnos, así como también proponer proyectos de lectura a través de actividades de comprensión que respondan a las prácticas lectoras que caracterizan al contexto universitario y a cada una de las disciplinas.

El campo influye de manera especial en el léxico. De manera que al tratarse del discurso de especialidad, en los textos utilizados en clase predomina la terminología propia del ámbito académico y científico. Esto determina que, al abordar las cuestiones de léxico en clase, se enfatice el significado del vocabulario de acuerdo con el contexto en el que aparecen y a las variaciones de sentido que puede haber de una especialidad a otra.

\subsection{TENOR}

En relación con el concepto de tenor, éste tiene que ver con las personas involucradas, sus roles sociales y la relación entre los interlocutores.

En este sentido, en nuestras clases tenemos en cuenta que nuestro alumno es un lector alóglota, quien no forma parte de la comunidad científica y discursiva del destinatario pensado por el autor, que escribe el texto pensando en un lector diferente. En este sentido, nuestro alumno se encuentra en desventaja dado que “sus conocimientos del código y de las referencias socioculturales son limitados" (Lucas, Vidal, 2006:96). Ante la situación dada, y al no ser nuestro alumno el lector previsto por el autor, "la tarea de comprender un texto en LE supone entonces un costo cognitivo y afectivo suplementario que se añade a la ya compleja tarea de leer" (Pastor, 2006: 104)

Esto nos lleva, como docentes, a intermediar entre el autor y el alumno-lector a través de proyectos de lectura planteados en las consignas de trabajo. Así, buscamos acercar las posiciones entre estos dos participantes del proceso de comunicación, planteando objetivos de lectura que respondan a la realidad del contexto en el que la misma se lleva a cabo, es decir, coherente con el ámbito universitario.

Un concepto clave que guía la definición de los proyectos de lectura que planteamos en clase es el de "aprender a aprender" (Pozo, 1999:307) ya que se relaciona con la función epistémica de la lectura, que es la función primordial de la lectura en el ámbito universitario. La misma, ligada a la construcción de conocimientos específicos propios de cada disciplina, es trabajada en nuestras clases a través de actividades en las que el alumno debe resolver situaciones problemáticas que requieren de la información contenida en 
los textos. Para ello, este alumno-lector deberá investigar, reflexionar y desarrollar estrategias propias, estimulando su creatividad y pensamiento lógico e incluso crítico en algunos casos. Se trata de generar situaciones de lectura encuadradas dentro de situaciones reales de aprendizaje de las diferentes disciplinas e inscriptas dentro del contexto de referencia del alumno. En este sentido, coincidimos con Cassany (2006:72) cuando afirma: "Cada escrito debe asociarse con una instrucción, con una actividad concreta y clara. La tarea deber formularse previamente a la lectura, precisamente para establecer una "motivación y un contexto". [Los propósitos] crean un vacío de interés, una incógnita que el aprendiz debe resolver leyendo el escrito. Al plantear la tarea en primer lugar, la lectura adquiere sentido. Leer y releer se convierten así como en la vida real- en el medio para resolver cosas" (Cassany, 2006: 72).

Así, por ejemplo, una de las actividades que predomina es la de completar o elaborar esquemas con información contenida en el texto leído. Esto le exige al alumno desarrollar procesos y estrategias de orden superior como la jerarquización de ideas, análisis, reorganización, asociaciones intra y extratextuales, síntesis, relaciones y confrontación con el conocimiento previo del sujeto, entre otros.

Otro aspecto relacionado con el concepto de tenor tiene que ver con la manera de trabajar las formas lingüísticas, no como estructuras gramaticales aisladas sino como el reflejo de las marcas personales, de modalización, del grado de implicación de los autores del discurso, de las relaciones entre los interlocutores y de la intención comunicativa. Así, por ejemplo, la enseñanza de los verbos modales no se realiza sólo a partir de una explicación formal de la estructura que estas formas presentan, sino que se plantean teniendo en cuenta la implicancia que el uso de estas tiene en relación con la intención comunicativa de los autores. Entonces, al trabajar un texto en el que aparecen ese tipo de verbos, guiamos a los alumnos a diferenciar los propósitos que el autor tiene al usar uno u otro verbo modal, que revela el grado de certeza de parte suya ante la información brindada.

Esto nos exige guiar al alumno en una lectura que va más allá de la interpretación del contenido del texto y ayudarlo a reconocer en los enunciados del autor marcas lingüísticas que revelan su manera de pensar y sentir frente a lo que explicita en el texto.

\subsection{MODO}

Por último, la variable modo está relacionada con la naturaleza de la comunicación, el canal (escrito en nuestro caso), el medio a través del cual se lleva a cabo la comunicación, así como los rasgos característicos de las prácticas discursivas según su función social.

Zaya (2012: 67) afirma que "El modo influye en los rasgos específicos del discurso, ya sea oral o escrito, en los recursos que intervienen en la coherencia y cohesión del texto, en la combinación del lenguaje 
verbal con otros lenguajes, en los usos relacionados con el medio de comunicación utilizado (prensa, radio, portal web, redes sociales...) etc."

Considerando esta variable, en nuestras clases trabajamos únicamente con el discurso escrito y focalizamos la atención en los rasgos de los textos del discurso académico. Se trabaja la comprensión lectora de textos auténticos que no han sufrido ningún tipo de modificación, es decir, no han sido "didactizados", respecto a la fuente de donde han sido extraídos. Los textos son presentados respetando el formato original tanto del texto como del paratexto.

Un punto central en este sentido es el trabajo explícito que hacemos en cuanto a la enseñanza de los géneros discursivos que habitualmente circulan en el ámbito universitario.

Coincidimos con Paula Carlino cuando afirma: "Enseñar géneros académicos es, entonces, posibilitar que los alumnos se incluyan en situaciones discursivas típicas de comunidades especializadas, según propósitos, significados y valores compartidos. Aprender a leer y escribir significa formarse para participar y pertenecer a ellas" (Carlino, 361: 2013)

Así, la lectura de textos tales como prólogos, reseñas críticas, abstracts de artículos de investigación, resúmenes de ponencias, artículos de investigación, artículos de revistas de divulgación científica, entre otros textos del género académico, va acompañada de actividades áulicas que apelan a las experiencias previas de los alumnos en la lectura de este tipo de textos, para luego explicitar las características distintivas del formato del texto.

De este modo, las consignas buscan destacar la estructura formal de los textos y llevar al alumno a establecer relaciones entre las partes que lo componen, focalizando en diferentes elementos sintácticos y lexicales que ponen en evidencia dichas relaciones.

Así, por ejemplo, se proponen actividades en las que el alumno debe reconocer y explicitar las relaciones de cohesión y coherencia como el caso de los pronombres personales, conectores, etc.

Por otra parte, una de las actividades de comprensión más usada y que tiene estrecha relación con la enseñanza de las estructuras formales de los textos es la confección o llenado de esquemas, mapas cognitivos o cuadros comparativos que implican la representación gráfica de la información del texto que originalmente está presentada de manera lineal. El uso de este tipo de actividad permite guiar al alumno a focalizar su atención no sólo en la información explícita presente en el texto, sino también en los implícitos, entendidos en función de los conocimientos previos y de los intereses del receptor.

Por otra parte, trabajar con esquemas permite reforzar la enseñanza de las convenciones formales de los géneros propios del discurso académico como un aporte significativo a la alfabetización académica de nuestros estudiantes. 


\section{REFLEXIONES FINALES}

Nuestro aporte desde la enseñanza de la lecto comprensión de textos académicos en inglés no pretende cubrir de manera absoluta la necesidad de alfabetizar académicamente.

Coincidimos con González Muñoz y otros (2021) cuando sostienen que "La competencia lectora consiste en la capacidad de construir conocimientos a través de la lectura y lograr un aprendizaje significativo. En esta tarea, el lector extrae, interpreta y reflexiona sobre la información y el proceso". En relación con esto, entendemos que para que nuestros estudiantes universitarios logren formarse profesionalmente de manera efectiva, necesitan desarrollar las competencias lectoras tanto en su lengua materna como, en el caso de nuestra asignatura, en inglés, propias del contexto disciplinar y académico del que forman parte. En tal sentido, creemos que nuestras clases son un espacio de exposición a textos de las disciplinas, en nuestro caso en inglés, así como también un lugar propicio para que nuestros alumnos reflexionen y tomen conciencia acerca del funcionamiento del lenguaje en este contexto, en un trabajo interdisciplinario con los especialistas de las diferentes áreas disciplinares. La aplicación de estrategias metacognitivas en clase permite al alumno desarrollar acciones conscientes para procesar la información del texto. La "metacognición implica la toma de conciencia del sujeto que aprende acerca de sus propios procesos y niveles de conocimiento, de cómo él puede alcanzar esos niveles y cómo éstos últimos pueden eventualmente ser modificados" (Caldera Bermúdez, 2007:251)

Quisiera destacar que, en nuestra Facultad, se han iniciado acciones a nivel institucional para la implementación de Talleres de Formación destinados a los docentes de las asignaturas de primer año de las diferentes carreras. Este es un primer paso para llevar adelante procesos de apoyo para la integración a la cultura universitaria de los alumnos ingresantes. Así, entre los ejes que se busca trabajar desde las cátedras encontramos el trabajo con las prácticas de lectura y escritura en la universidad como prácticas epistémicas. Si bien este es sólo el inicio, pone en evidencia la preocupación de la institución acerca de la necesidad de que la universidad asuma la responsabilidad de generar acciones concretas para la inserción exitosa de los estudiantes en la cultura académica.

Para finalizar, quisiera decir que el hecho de que en algunas instituciones universitarias de nuestro país se estén poniendo en práctica algunas iniciativas hacia la alfabetización académica desde las disciplinas, lo mismo que el hecho de que en algunos encuentros científicos se generen debates y discusiones acerca de este tema, pone en evidencia el interés y preocupación por esta problemática, que al ser abordada redundará sin duda en una mejora de la calidad académica. 


\section{REFERENCIAS BIBLIOGRÁFICAS.}

BAJTIN, M. (1990) Estética de la creación verbal. Mexico: Siglo Veintiuno.

CALDERA, R.; BERMÚDEZ, A. (2007) Alfabetización académica: comprensión y producción de textos en Educere, [en linea] Vol. 11, N 37 (abril-junio) 2007, pp. 247-255, Universidad de los Andes, Venezuela. [Fecha de consulta: 2 de octubre de 2015] Disponible en: <http://www.redalyc.org/articulo.oa?id=35603710> ISSN 1316-4910

CARLINO, P. (2005) Escribir, leer y aprender en la universidad. Una introducción a la alfabetización académica. Buenos Aires: Fondo de Cultura Económica de Argentina.

CARLINO, P. (2013) Alfabetización Académica Diez Años Después en Revista Mexicana de Investigación Educativa [en linea] 2013, 18 (Sin mes) pp.355-381: [Fecha de consulta: 2 de octubre de 2015] Disponible en:<http://redalyc.org/articulo.oa?id=14025774003> ISSN 1405-6666)

CASSANY, D. (2006): Taller de textos. Leer, escribir y comentar en al aula. Barcelona: Paidós

CASTRO AZUARA, M. C. (2011) Alfabetización académica y géneros discursivos: los textos recepcionales en el nuevo contexto de titulación en la universidad, en Memorias del XII Encuentro Nacional de Estudios en Lenguas, Facultad de Filosofía y Letras, Universidad Autónoma de Tlaxcala.

CHRISTIE, F.; UNSWORTH, L. (2000) Developing socially responsible language research. En: Unsworth, L. (ed). Researching Language in Schools and Communities. Functional Linguistic Perspective. London, Cassell. Cap. 1. Traducción: Estela Inés Moyano

CUESTAS, A.; IACOBONI, G. N. (2008) El fortalecimiento de la alfabetización académica desde la lectocomprensión en lengua extranjera: Una experiencia práctica. Puertas Abiertas, en Memoria Académica. Disponible en: http://www.memoria.fahce.unlp.edu.ar/art_revistas/pr.4557/pr.4557.pdf

DORRONZORO, M. I.; KLETT, E. (2006) Leer en Lengua Extranjera en la universidad: marco teórico y transposición didáctica, en Pastor, R.; Sibaldi, N.; Klett, E. (2006) Lectura en Lengua Extranjera. Una mirada desde el Receptor. Tucumán: Centro de Estudios Interculturales, Facultad de Filosofía y Letras, UNT, pp. 57-72.

DORRONZORO, M. I. (2009) Lectura en lengua extranjera y escritura en lengua materna: ¿Qué relaciones?, en Klett, E. et al. Construyendo la Didáctica de las Lenguas Extranjeras. Buenos Aires: Araucaria editora, pp. 83-100.

EGGINS, S; MARTIN, J. R. (2000) Géneros y registros del discurso, en Van Dijk, T. (2000) El Discurso como Estructura y Proceso, pp. 335-371. Barcelona, España: Editorial Gedisa.

GONZÁLEZ MUÑOZ, J. et al (2021) La lectoescritura como capacidad cognitiva: procesos componentes. Intervención en educación primaria, en South Florida Journal of Development. Miami, Vol. 2, N 1, pp. 1191-1203, April-June 2021.

LUCAS, M.; VIDAL, M. (2006) Lectores universitarios, tareas y con-textos. Fundamentos para una opción didáctica diferente, en en Pastor, R.; Sibaldi, N.; Klett, E. (2006) Lectura en Lengua Extranjera. Una mirada desde el Receptor. Tucumán: Centro de Estudios Interculturales, Facultad de Filosofía y Letras, UNT, pp.85-97. 
PASTOR, R. (2005a) El discurso del estudiante universitario: características de un género textual. En Actas del X Congreso Nacional de Lingüística. Salta: Universidad Católica de Salta. CD-Rom

PASTOR DE DE LA SILVA, R. (2005b). Lectura y Socialización textual: la relación dialéctica textolector. En Actas I Congreso de Lecturas Múltiples. Fac. Cs. Educ, UNER. <http://www.fcedu.uner.edu.ar/clm/dela\%20silva.html> [27 de agosto de 2006. [ Links ]]

PASTOR, R. (2006) Lectura en lengua extranjera y competencia textual en estudiantes universitarios. En Pastor, R, Sibaldi, N., Klett, E. (comp.). Lectura en lengua Extranjera. Una mirada desde el receptor. Tucumán: Centro de Estudios Interculturales, Facultad Filosofía y Letras, UNT, pp. 98-122.

POZO, J. I. (1999) Aprendices y Maestros. La Nueva Cultura del Aprendizaje. Madrid: Alianza Editorial. RODRÍGUEZ BELLO, L., VILLEGAS, C. (2008). Una mirada estética a la lectura y la escritura, desde Bajtin. Investigación y Postgrado [en línea] 2008, vol. 23. Recuperado el 12-09.2012 de: http://redalyc.uaemex.mx/src/inicio/ArtPdfRed.jsp?iCve=65815752005. ISSN 1316-0087.

SWALES, M. (1990). Genre Analysis. English in academic and research settings. Cambridge: Cambridge University Press.

VAN DIJK, T. (1983): La ciencia del texto. Un enfoque interdisciplinario. Paidós. Buenos Aires. Argentina

ZAYAS, F. (2012) Los géneros discursivos y la enseñanza de la composición escrita, en Revista Iberoamericana de Educación, № 59, 2012, pp 63-85, (1022-6508). España: Universidad de Valencia. 